Istanbul Finance Congress, November 1-2, 2018, Istanbul, Turkey.

\title{
THE ROLE OF CAPITAL MOVEMENTS AND CAPITAL MARKETS ON ECONOMIC GROWTH: A PANEL DATA ANALYSIS FOR DEVELOPING COUNTRIES
}

\section{DOI: 10.17261/Pressacademia.2018.974}

PAP-IFC- V.8-2018(6)-p.24-28

\section{Serpil Kuzucu}

Beykoz University, Faculty of Business Management and Administrative Sciences, Istanbul, Turkey. serpilkuzucu@beykoz.edu.tr, ORCID: 0000-0003-2949-4086

\section{To cite this document}

Kuzucu, S. (2018). The role of capital movements and capital markets on economic growth: panel data analysis for developing countries. PressAcademia Procedia (PAP), V.8, p.24-28.

Permanent link to this document: http://doi.org/10.17261/Pressacademia.2018.974

Copyright: Published by PressAcademia and limited licenced re-use rights only.

\begin{abstract}
Purpose - The effects of foreign capital inflows and credit expansion on economic growth of developing countries are controversial because it is claimed that they cause business cycle and financial crises. In order to look for answers to the discussion, the impacts of foreign capital flows and credit size on economic growth are questioned in this paper.

Methodology - The data of selected developing economies over the period between 2005 and 2015 are investigated by panel data analysis. Findings - According to the results of analysis, while foreign direct investment is statistically significant and has a positive impact on economic growth, there isn't a significant relation between portfolio investment and economic growth. Domestic credit provided by financial sector, current account deficit and inflation have not significant impact on economic growth. On the other hand, foreign exchange rate and unemployment are negatively associated with economic growth.

Conclusion - This study finds that foreign direct investment increases economic growth in developing countries, but portfolio investment does not have any impact on economic growth. In addition, increase in domestic credit size is not associated with economic growth in developing countries.
\end{abstract}

Keywords: developing countries, economic growth, foreign direct investment, portfolio investment JEL Codes: C33, F21, F43

\section{SERMAYE HAREKETLERININ VE SERMAYE PIYASALARININ EKONOMIK BÜYÜMEDEKI ROLÜ: GELIŞMEKTE OLAN ÜLKELERIN BIR PANEL VERI ANALIZi}

ÖZET

Amaç - Gelişmekte olan ülkelere yönelik yabancı sermaye hareketleri ve kredi genişlemesinin ekonomik büyüme üzerindeki etkisi, -iş döngüsü ve finansal krizlere de neden olduğu iddiasıyla- tartışmalıdır. Bu çalışmada, söz konusu tartışmaya cevap aramak amacıyla sermaye hareketleri ve kredi büyüklüğünün ekonomik büyüme üzerindeki etkisi sorgulanmıştır.

Yöntem - Gelişmekte olan seçilmiş ekonomilerin 2005 - 2015 yılları arasındaki verileri panel veri analizi yöntemi ile incelenmiştir.

Bulgular-Analiz sonuçlarına göre, doğrudan yabancı sermaye yatırımlarının ekonomik büyüme üzerinde istatistiksel olarak anlamlı ve pozitif etkisi bulunurken, portföy yatırımları ile ekonomik büyüme arasında istatistiksel olarak anlamlı ilişki bulunamamıştır. Finansal sektör tarafından sağlanan krediler, cari açık ve enflasyonun ekonomik büyüme ile ilişkisinin olmadığı görülürken, döviz kuru ve işsizliğin ekonomik büyüme ile negatif ilişkili olduğu sonucuna ulaşılmıştır.

Sonuç- Gelişmekte olan ülkelere doğrudan yabancı yatırımlar olarak gelen sermaye hareketlerinin ekonomik büyümeye katkı sağladığı, ancak portföy yatırımlarının gelişmekte olan ekonomilerin büyümesine olumlu ya da olumsuz etkisinin olmadığı sonucu elde edilmiştir. Ayrıca yurtiçi kredilerdeki artışın da ekonomik büyümeye etkisinin olmadığı görülmüştür.

Anahtar Kelimeler: gelişmekte olan ülkeler, ekonomik büyüme, doğrudan yabancı sermaye yatırımları, portföy yatırımları. JEL Kodları: C33, F21, F43

\section{GiRiş}

Yabancı sermaye hareketlerinin gelişmekte olan ülkelerin ekonomik büyümesi üzerindeki etkileri tartışmalı bir konudur. Yabancı sermaye gelişmekte olan ülkelere uzun vadeli doğrudan yabancı yatırımlar şeklinde girdiğinde ekonomik büyümeye olumlu katkılarının olduğu görüşü hakimdir. Doğrudan yabancı yatırımlar özellikle teknoloji transferinin önemli bir kaynağı olarak görülmektedir. Doğrudan yabancı yatırımlar, girdiği ülkeye yönetim ve uygulama becerisi konusunda yenilikler getirmesi, teknoloji transferi sağlaması, yeni istihdam 
olanakları yaratması gibi nedenlerle ekonomik büyümeyi olumlu yönde etkilemektedir. Diğer taraftan gelişmekte olan ülkelere kısa vadeli olarak giren portföy yatırımları ise ekonomilerde istikrarsızıı yaratması ve döviz krizi veya borç krizi gibi finansal krizlere neden olması gibi sebeplerle eleştirilmektedir.

Çalışmada doğrudan yabancı sermaye ile portföy yatırımlarının gelişmekte olan ülkelerin ekonomik büyümelerindeki etkileri araştırılmıştır. Bu amaçla, gelişmekte olan 52 ülkenin verileri panel veri analizi yöntemi kullanılarak incelenmiştir. Çalışma dört bölümden oluşmaktadır. Bir sonraki bölüm doğrudan yabancı sermaye ve portföy yatırımları ile ekonomik büyüme arasındaki ilişkiyi araştıran literatür çalışmalarına ayrılmıştır. Üçüncü bölümde çalışmada kullanılan model, yöntem ve veri setine yer verilmiştir. Dördüncü bölümde regresyon tahmin sonuçları değerlendirilmiştir. Son bölüm ise sonuç kısmına ayrılmıştır.

\section{LITERATÜR TARAMASI}

Doğrudan yabancı sermayenin ekonomik büyümeye katkı sağladığı sonucuna ulaşan birçok çalışma bulunmaktadır. Bu çalışmalar, doğrudan yabancı yatırımların istihdam yarattığını, yönetim becerisi ve teknoloji transferi sağladığını, dışsallıklar ve yayılma etkisi yoluyla ekonomik büyümeyi arttırdığını doğrulamaktadır.

Doğrudan yabancı sermayenin ekonomik büyüme üzerindeki etkisini inceleyen De Mello (1999), Borensztein vd (1999), Nair-Reichert ve Weinhold (2001) ve Makki ve Somwaru (2004) doğrudan yabancı sermayenin ekonomik büyümeyi desteklediği sonucuna ulaşmışlardır. De Mello (1999), doğrudan yabancı sermayenin ev sahibi ülkede sermaye birikimi, üretim ve faktör verimliliğine etkisini incelemiştir. 1970 ve 1990 aralığında 32 ülke verisiyle yaptığı çalışmada uzun dönemde doğrudan yabancı sermayenin teknolojik iyileşme ve yayılma etkisi yoluyla ekonomik büyümeyi arttırdığını bulmuştur. Borensztein vd (1999) gelişmekte olan 69 ülkenin 1970 ve 1989 yılları arasındaki verilerinin incelediği çalışmada, doğrudan yabancı yatırımların teknoloji transferinin önemli bir aracı olduğu ve yerli yatırımlardan daha fazla büyümeyi desteklediği sonucuna ulaşmışlardır. Ayrıca, doğrudan yabancı yatırımların verimliliğinin ev sahibi ülkenin belirli bir seviyede beşeri sermaye stokuna sahip olmasına dayandığını belirtmektedirler.

Nair-Reichert ve Weinhold (2001) gelişmekte olan 24 ülkenin 1971 ve 1995 arasındaki verilerini inceledikleri çalışmada ekonomik büyümenin doğrudan yabancı sermaye ile ilişkili olduğunu ancak ülkeler arasında farklılıklar olduğunu bulmuşlardır. Makki ve Somwaru (2004) içsel büyüme teorisine dayanan bir modelle doğrudan yabancı yatırımların ve ticaretin ekonomik büyüme üzerindeki etkisini incelemiştir. Ayrıca doğrudan yabancı yatırımların ticaret, insan sermayesi ve yurtiçi yatırımlarla etkileşimini incelemiştir. 66 gelişmekte olan ülkenin 1971'den 2000'e kadar olan verilerinden faydalanarak yaptığı çalışmada doğrudan yabancı yatırımların ve ticaretin gelişmekte olan ülkelerde ekonomik büyümeyi arttırdığı sonucuna ulaşmışlardır. Bununla beraber, doğrudan yabancı yatırımlar ile ticaret arasında güçlü olumlu yönde bir etkileşim olduğunu da belirtmektedirler.

Doğrudan yabancı yatırımın ev sahibi ülkeye fayda sağlaması için ülkenin belirli bir finansal gelişmişliğe ulaşmış olması gerektiğini ortaya koyan çalışmalar bulunmaktadır. Alfaro vd. (2000) 90 ülkenin 1981 ve 1997 yılları arasındaki verilerini kullanarak doğrudan yabancı sermayenin ekonomik büyümeye etkisini inceledikleri çalışmada, doğrudan yabancı sermayenin ekonomik büyümede önemli rol oynadığını bulmuşlardır. Doğrudan yabancı sermayenin finansal sektörün gelişmiş olduğu ülkelerde finansal sektörün az gelişmiş olduğu ülkelere kıyasla daha fazla ekonomik büyüme sağladığı sonucuna ulaşmışlardır. Lee ve Chang (2009) doğrudan yabancı yatırımlar ile ekonomik büyüme arasındaki uzun dönem ilişkide finansal gelişmişliğin rolünü incelemiştir. 37 ülkeyi kapsayan çalışmasında, doğrudan yabancı yatırımlar, ekonomik büyüme ve finansal gelişmişlik arasındaki ilişkinin kısa dönemde zayıf ancak uzun dönemde kuvvetli olduğunu bulmuşlardır.

Doğrudan yabancı yatırımların ekonomik büyüme ile ilişkisinin olmadığını gösteren çalışmalar da bulunmaktadır. Carkovic ve Levine (2002) 1960 ve 1995 yılları arasında 72 ülke verisini kullanarak yaptıkları çalışmada doğrudan yabancı yatırımların ekonomik büyüme üzerinde etkisi bulunmadığını göstermişlerdir. Durham (2004) 1979 ve 1997 yılları arasında 80 ülkenin verilerinden yararlanarak yaptığı çalışmada hem doğrudan yabancı yatırımların hem de portföy yatırımlarının ekonomik büyümeye etkisinin olmadığını bulmuşlardır.

Yabancı sermaye yatırımlarının ekonomik büyümeye olumlu katkısı olduğunu savunan çalışmalar çoğunluktadır. Doğrudan yabancı yatırımlar geleneksel olarak diğer yabancı sermaye hareketlerinden daha yararlı olarak görülmektedir. Gelişmekte olan ülkelere giren kısa vadeli sermaye hareketleri ise ekonomilerde istikrarsızlık yaratması ve finansal krizlere neden olmasından dolayı olumsuz olarak değerlendirilmektedir. Portföy yatırımlarının ekonomik büyüme ile ilişkisine yer veren çalışmalarda, ekonomik büyümeyi olumsuz yönde etkilediği sonuçlarının yanı sıra ekonomik büyümeyi olumlu yönde etkilediği sonuçları da bulunmaktadır.

Choong vd. (2010) gelişmekte olan 51 ülkenin 1988 ve 2002 dönemi verilerini kullanarak yaptıkları çalışmada doğrudan yabancı yatırımlar ile portföy yatırımlarının ekonomik büyüme üzerindeki etkisini araştırmışlardır. Doğrudan yabancı yatırımların ekonomik büyüme üzerinde pozitif etkisinin olduğunu, portföy yatııımlarının ise negatif etkisinin olduğunu bulmuşlardır. Ferreira ve Laux (2009) 1988-2001 döneminde 50 ülkenin verileriyle yaptığı çalışmada portföy yatırımlarının hem gelişmiş hem de gelişmekte olan ülkelerde ekonomik büyümeyi arttırdığını bulmuşlardır. Aizenman vd (2013) de ekonomik büyüme ile doğrudan yabancı yatırımlar ve portföy yatırımları arasındaki ilişkiyi incelemiştir. 1990 ve 2010 yılları arasında 100 ülkenin verileriyle yapılan çalışmada doğrudan yabancı yatırımların ekonomik büyüme üzerinde pozitif etkisinin olduğunu, portföy yatırımlarının küçük ve istikrarsız bir etkisinin olduğunu bulmuşlardır.

Ekonomik büyüme ile finansal açıklık arasındaki ilişkiyi inceleyen çalışmalar da bulunmaktadır. Chanda (2005) gelişmekte olan 57 ülkede 1975 ve 1995 yılları arasındaki verileri kullanarak yaptıkları çalışmada sermaye kontrollerinin ekonomik büyümeyi olumsuz etkilediğini bulmuşlardır. Bussiere vd. (2008) 45 gelişmiş ve gelişmekte olan ülkenin 1980 ve 2002 yılları arasındaki verilerden faydalanarak yaptıkları çalışmada finansal açıklık ve ekonomik büyüme arasındaki ilişkiyi test etmişlerdir. Çalışmalarında finansal açıklığın kısa dönemde ekonomik büyümeyi destekleyebileceğini, ancak uzun dönemde etkisinin olmadığını bulmuşlardır. Klein ve Olievei (2008) 138 ülkenin 1986 ve 1995 yılları arasındaki verilerinden yararlanılarak yaptıkları çalışmada sermaye hareketlerinin finansal derinlik ve ekonomik büyüme üzerinde etkili olduğunu bulmuşlardır. Sermaye hareketlerinin kısıtlandığı ülkelerle karşılaştırıldığında finansal liberalizasyon olan ülkelerde finansal derinliğin arttığını ve daha fazla ekonomik büyüme sağladıklarını bulmuşlardır. Kose vd. (2009) finansal açıklığın ekonomik büyüme ve 
verimlilik üzerindeki etkisini araştırdıkları çalışmalarında hem doğrudan yabancı yatırımların hem de portföy yatırımlarının ekonomik büyümeyi arttırdığını bulmuşlardır.

Portföy yatırımlarının finansal krizlere neden olup olmadığını inceleyen çalışmalarda portföy yatırımlarının finansal kriz riskini arttırdığını gösteren sonuçlar bulunmaktadır. Bordo vd. (2010) döviz ve borç krizlerini inceledikleri çalışmalarında, yabancı para ile borçlanmanın döviz ve borç krizlerini tetiklediğini ve bunun da önemli ekonomik küçülmelere yol açtığını savunmaktadırlar. Reinhart ve Reinhart (2008) 181 ülkenin 1980-2007 dönemindeki verileriyle yaptıkları çalışmada yüksek miktarda sermaye girişlerinin ev sahibi ülkede finansal ve ekonomik kriz olasılığını arttırdığını bulmuşlardır.

\section{YÖNTEM, VERI SETI VE MODEL}

Çalışmada gelişmekte olan ülkelerde sermaye hareketlerinin ekonomik büyüme üzerindeki etkisini araştırmak amaçlanmıştır. Bu amaçla, aşağıdaki model tahmin edilmiştir;

GDPi, $t=B_{0}+B_{1} F D I i, t+B_{2} P l i, t+B_{3} C R E D I T i, t+B_{4} C U R \_A C C i, t+b_{5} I N F i, t+b_{6} F X i, t+b_{7} U N E M P i, t+\varepsilon i, t$

Modelde i ülkeleri, $\mathrm{t}$ ise zaman boyutunu göstermektedir. GDP ekonomik büyümeyi, FDI doğrudan yabancı yatırımları, PI portföy yatırımlarını, CREDIT yurtiçi kredi hacmini, CUR_ACC cari hesap dengesini, INF enflasyonu, FX döviz kurunu, UNEMP ise işsizliği ifade etmektedir. Ekonomik büyüme için GSYIH (gayrisafi yurtiçi hasıla)'nın yıllık yüzde değişimi alınmıştır. Doğrudan yabancı yatırımları için net yabancı doğrudan yatırımların GSYIH'ya oranı, portföy yatırımları için net portföy yatırımlarının GSYIH'ya oranı, kredi hacmi için bankaların özel sektöre sağladığı kredilerin GSYIH'ya oranı, cari hesap dengesi için cari İşlemler hesabının GSYIH'ya oranı, enflasyon için tüketici fiyatlarındaki yıllık değişim, döviz kuru için döviz kurundaki yıllık değişim, işsizlik için işsiz işgücünün toplam istihdama oranı kullanılmıştır. Açıklayıcı değişkenler ve beklenen etkileri Tablo 1'de gösterilmektedir.

Tablo 1: Değişkenler ve Beklenen Etkileri

\begin{tabular}{llll} 
Değişkenler & Sembol & Tanım & Beklenen Etki \\
\hline $\begin{array}{l}\text { Ekonomik büyüme } \\
\text { Doğrudan Yabancı Yatırımlar }\end{array}$ & gdp & GSYıH'nın yıllık yüzde değişimi & bağımlı değişken \\
$\begin{array}{l}\text { Portföy Yatırımları } \\
\text { Kredi Hacmi }\end{array}$ & $\mathrm{fdi}$ & Net yabancı doğrudan yatırımların GSYıH'ya oranı & + \\
& Credit & Bet portföy yatııılarının GSYıH'ya oranı & $+/-$ \\
& & GSYıH'ya oranı & \\
Cari Hesap Dengesi & curr_acc & Cari İşlemler hesabının GSYıH'ya oranı & + \\
$\begin{array}{l}\text { Enflasyon } \\
\text { Döviz Kuru }\end{array}$ & inf & Tüketici fiyatlarındaki yıllık değişim & - \\
Işsizlik & fx & Döviz kurundaki yıllık değişim & - \\
\hline
\end{tabular}

Çalışmada 2005 ve 2015 yılları arasında gelişmekte olan 52 ülkenin yıllık verileri kullanılmıştır. Veriler Dünya Bankası Dünya Kalkınma Göstergeleri veri setinden elde edilmiştir. Çalışmada GSYIH'sı 20 milyar USD'ın üzerindeki ülkeler veri setine dahil edilmiştir. Model tahmin yöntemi olarak panel veri analizi yöntemi kullanılmıştır.

Kurulan modeli tahmin etmek için önce modeli oluşturan değişkenlerin zaman içinde birim kök içerip içermediği test edilmiştir. Genişletilmiş Dickey Fuller (ADF) testi sonuçlarına göre enflasyon değişkeni hariç tüm değişkenler durağandır. Phillips-Perron testi sonuçlarına göre ise tüm değişkenler durağandır. Birim kök testleri Tablo 2'de yer almaktadır.

Tablo 2: Birim Kök Testleri

\begin{tabular}{lllll} 
Değikenler & $\begin{array}{l}\text { Fisher-PP } \\
\text { ki-kare istatistiği }\end{array}$ & p-değeri & $\begin{array}{l}\text { Fisher-ADF } \\
\text { ki-kare istatistiği }\end{array}$ & p-değeri \\
\hline gdp & $231.67^{* * *}$ & 0.00 & $353.72 * * *$ & 0.00 \\
credit & $136,18^{* *}$ & 0.45 & $285.08^{* * *}$ & 0.00 \\
fdi & $331.08^{* * *}$ & 0.00 & $341.93^{* * *}$ & 0.00 \\
pi & $267.49^{* * *}$ & 0.00 & $223.62^{* * *}$ & 0.00 \\
curr_acc & $246.47^{* * *}$ & 0.00 & $346.66^{* * *}$ & 0.00 \\
inf & $331.60^{* * *}$ & 0.00 & 105.63 & 0.38 \\
fx & $186.19^{* * *}$ & 0.00 & $171.91 * * *$ & 0.00 \\
unemp & $371.31^{* * *}$ & 0.00 & $322.49 * * *$ & 0.00 \\
\hline
\end{tabular}

Not: ${ }^{*}, * *$, ve ${ }^{* * *}$ sırasıyla $\% 10, \% 5$ ve $\% 1$ anlamlılık düzeylerini ifade etmektedir. 


\section{BULGULAR}

Çalışmada panel veri analizi ile model tahmin edilmiştir. Panel veri modelinin tahmin edilmesinde sabit etkiler (fixed effect) ve tesadüfi etkiler (random effects) olmak üzere iki yöntem bulunmaktadır. Hausman testi sonuçlarına göre tesadüfi etkiler modelinin regresyon analizinde uygun olacağı belirlenmiştir. Hausman testi sonuçları Tablo 3'de bulunmaktadır.

Tesadüfi etkiler yöntemi ile tahmin edilen modelde değişen varyans probleminin tespiti için Breusch-Pagan Lagrange çarpanı testi ve otokorelasyon problemi için ise Bhargava vd. Durbin-Watson testi ve Baltagi-Wu LBI testleri uygulanmıştır. Sonuçlara göre modelde değişen varyans ve otokorelasyon problemleri bulunmaktadır. Test sonuçları Tablo 3'de verilmiştir.

Tablo 3: Temel Varsayım Testleri

\begin{tabular}{lll}
\hline $\begin{array}{l}\text { Hausman Test } \\
\text { chi2 }\end{array} \quad 6.17$ & Prob>chi2 & 0.5198 \\
Breusch-Pagan Lagrange çarpanı & \\
chibar2(01) $=39.85$ & Prob $>$ chibar2 & 0.0000 \\
Bhargava vd. DW & 1.4486787 & \\
Baltagi-Wu LBI & 1.8076134 & \\
\hline
\end{tabular}

Değişen varyans ve otokorelasyon problemlerinin çözümü için dirençli standard hatalar sağlayan Arellano-Froot-Rogers tahmincisi kullanılmıştır. Regresyon analizinin sonuçları Tablo4'de yer almaktadır.

Tahmin sonuçlarına göre bağımsız değişkenlerden doğrudan yabancı yatırımlar, döviz kurları ve işsizlik istatistiki olarak anlamlı bulunmuştur. Doğrudan yabancı yatırımlar ekonomik büyümeyi olumlu yönde etkilemektedir. Döviz kurları ile işsizlik ise ekonomik büyümeyi olumsuz yönde etkilemektedir. Değişkenler içinde ekonomik büyüme üzerindeki etkisi en büyük olan faktör doğrudan yabancı yatırımlardır. Portföy yatırımları, yurtiçi krediler, cari hesap dengesi ve enflasyon ise istatistiki olarak anlamsız bulunmuştur. Bu durumda bu değişkenlerin ekonomik büyüme üzerinde etkisi bulunmamaktadır.

Tablo 4: Panel Veri Analizi Tesadüfi Etkili Modelin Tahmin Sonuçları

\begin{tabular}{|c|c|c|}
\hline Değişkenler & Katsayı & t-istatistik \\
\hline fdi & $0.2291^{*}$ & 1.80 \\
\hline pi & -0.0651 & -0.95 \\
\hline credit & -0.0137 & -1.50 \\
\hline curr_acc & 0.0324 & 0.79 \\
\hline inf & -0.0016 & -0.04 \\
\hline$f x$ & $-0.1040 * * *$ & -3.32 \\
\hline unemp & $-0.1415^{* *}$ & -2.71 \\
\hline cons & $0.0577 * * *$ & 7.23 \\
\hline gözlem sayısı & 478 & 0.2152 \\
\hline grup sayısı & 52 & Wald ki-kare $36.09 * * *$ \\
\hline
\end{tabular}

Not: ${ }^{*}, * *$ ve $* * *$ sırasıyla $\% 10, \% 5$ ve $\% 1$ anlamlılık düzeylerini ifade etmektedir.

\section{SONUÇ}

Çalışmada, sermaye hareketlerinin gelişmekte olan ülkelerde ekonomik büyüme ile ilişkisi 2005-2015 dönemi verileriyle araştırılmıştır. Gelişmekte olan ülkelerde, doğrudan yabancı yatırımlar olarak gelen sermaye hareketleri ekonomik büyümeye katkı sağlamaktadır. Ancak portföy yatıımlarının olumlu ya da olumsuz etkisini bulunmamaktadır. Doğrudan sermaye yatııılarının ekonomik büyümeyle pozitif yönde ilişkisi model tahminindeki beklenen etkisi ile uyumludur. Ayrıca literatürde yabancı sermaye yatırımlarının ekonomik büyümeye olumlu katkısı olduğunu bulan çalışmaları (Borensztein vd, 1999; De Mello, 1999; Nair-Reichert ve Weinhold, 2001; Makki ve Somwaru, 2004) da desteklemektedir.

Döviz kuru ekonomik büyümeyi olumsuz yönde etkilemektedir. Bu durum, gelişmekte olan ülkelerde döviz kurlarının yükselmesi ve ulusal paranın değer kaybetmesi üretimi ithal girdiye dayanan ülkelerde ekonomik büyümeyi olumsuz etkilediği ile açıklanabilir. Ayrıca kısa vadeli sermaye hareketleri ev sahibi ülkede döviz kuru oynaklığına neden olabilmektedir. Döviz kuru oynaklığı da beklentileri ve ekonomik ortamı olumsuz yönde etkilediğinden ekonomik büyümeye olumsuz katkıları olması mümkündür. İssizlik oranın artması da ekonomik büyümeyi olumsuz yönde etkilemektedir. 


\section{KAYNAKLAR}

Aizenman, J., Jinjarak, Y., \& Park, D. (2013). Capital flows and economic growth in the era of financial integration and crisis, 19902010. Open Economies Review, 24(3), 371-396.

Alfaro, L., Chanda, A., Kalemli-Ozcan, S., \& Sayek, S. (2004). FDI and economic growth: the role of local financial markets. Journal of International Economics, 64(1), 89-112.

Bordo, M. D., Meissner, C.M. \& Stuckler,D. (2010). Foreign currency debt, financial crises and economic growth: A long-run view, Journal of International Money and Finance, 29: 642-665.

Borensztein, E., De Gregorio, J., \& Lee, J. W. (1998). How does foreign direct investment affect economic growth? 1. Journal of International Economics, 45(1), 115-135.

Bussiere, M. \& Marcel Fratzscher. (2008). Financial Openness and Growth: Shortrun Gain, Long-run Pain, Review of International Economics, 16, 1: 69-95.

Carkovic, M. ve Levine, R. (2002). Does Foreign Direct Investment Accelerate Economic Growth?. Working Paper, University of Minnesota Department of Finance. Available at SRN: https://ssrn.com/abstract=314924 or http://dx.doi.org/10.2139/ssrn.314924

Chanda, A. (2005). The influence of capital controls on long run growth: Where and how much? Journal of Development Economics, 77: 441-466.

Choong, C.K., Ahmad, Z., Zulkornain, Y. \& Habibullah, M.S. (2010). Private capital flows, stock market and economic growth in developed and developing countries: A comparative analysis, Japan and the World Economy 22: 107-117.

De Mello, L. R. (1999). Foreign direct investment-led growth: evidence from time series and panel data. Oxford economic papers, 51(1), 133-151.

Durham, K. B. (2004). Absorptive capacity and the effect of foreign direct investment and equity foreign portfolio investment on economic growth. European Economic Rewiev, 48:285-306.

Ferreira, M. A. \& Laux, P.A. (2009). Portfolio flows, volatility and growth. Journal of International Money and Finance, $28,271-292$.

Klein, M. W., \& Olivei, G. P. (2008). Capital account liberalization, financial depth, and economic growth. Journal of international money and finance, $27(6), 861-875$.

Kose, M.A., Prasad, E.S. \& Terrones, M.E. (2009). Does openness to international financial flows raise productivity growth? Journal of International Money and Finance, 28, 554-580.

Lee, C. C., \& Chang, C. P. (2009). FDI, financial development, and economic growth: international evidence. Journal of applied economics, 12(2), 249-271.

Makki, S. S., \& Somwaru, A. (2004). Impact of foreign direct investment and trade on economic growth: Evidence from developing countries. American Journal of Agricultural Economics, 86(3), 795-801.

Nair-Reichert, U., \& Weinhold, D. (2001). Causality tests for cross-country panels: a New look at FDI and economic growth in developing countries. Oxford bulletin of economics and statistics, 63(2), 153-171.

Reinhart, C. \& Reinhart, V. (2009). Capital Flow Bonanzas: An Encompassing View of the Past and Present. NBER Macroeconomics Annual, University of Chicago Press. 